\title{
2 Relative importance of tree species richness, tree functional type, and microenvironment for soil macrofauna communities in European forests
}

\author{
Pierre Ganault ${ }^{1}{ }^{10} \cdot$ Johanne Nahmani ${ }^{1} \cdot$ Stephan Hättenschwiler ${ }^{1} \cdot$ Lauren Michelle Gillespie $^{1}$. \\ Jean-François David ${ }^{1} \cdot$ Ludovic Henneron $^{2,3}$. Etienne lorio $^{4}$. Christophe Mazzia ${ }^{5}$ - Bart Muys ${ }^{6}$. Alain Pasquet ${ }^{7}$. \\ Luis Daniel Prada-Salcedo ${ }^{8,9}$. Janna Wambsganss ${ }^{10}$. Thibaud Decaëns ${ }^{1}$
}

\section{Received: 19 June 2020 / Accepted: 26 April 2021}

(c) The Author(s), under exclusive licence to Springer-Verlag GmbH Germany, part of Springer Nature 2021

\section{Abstract}

Soil fauna communities are major drivers of many forest ecosystem processes. Tree species diversity and composition shape soil fauna communities, but their relationships are poorly understood, notably whether or not soil fauna diversity depends on $\mathbf{A Q 1}$ tree species diversity. Here, we characterized soil macrofauna communities from forests composed of either one or three tree species, located in four different climate zones and growing on different soil types. Using multivariate analysis and model averaging we investigated the relative importance of tree species richness, tree functional type (deciduous vs. evergreen), litter quality, microhabitat and microclimatic characteristics as drivers of soil macrofauna community composition and structure. We found that macrofauna communities in mixed forest stands were represented by a higher number of broad taxonomic $\mathbf{A Q 2}$ groups that were more diverse and more evenly represented. We also observed a switch from earthworm-dominated to predator-dominated communities with increasing evergreen proportion in forest stands, which we interpreted as a result of a lower litter quality and a higher forest floor mass. Finally, canopy openness was positively related to detritivore abundance and biomass, leading to higher predator species richness and diversity probably through trophic cascade effects. Interestingly, considering different levels of taxonomic resolution in the analyses highlighted different facets of macrofauna response to $\mathbf{A Q 3}$ tree species richness, likely a result of both different ecological niche range and methodological constraints. Overall, our study supports the positive effects of tree species richness on macrofauna diversity and abundance through multiple changes in resource quality and availability, microhabitat, and microclimate modifications.

Keywords Community ecology $\cdot$ Forest ecosystems $\cdot$ Biodiversity-ecosystem functioning $\cdot$ Aboveground-belowground linkages

\section{Communicated by Stefan Scheu .}

\section{Pierre Ganault} pierre.ganault@gmail.com

1 EPHE, IRD, CEFE, University of Montpellier, CNRS, University of Paul-Valéry Montpellier, Montpellier, France

2 UNIROUEN, ECODIV, Place E. Blondel, UFR Sciences et Techniques, Normandie University, 76821 Mont Saint Aignan cedex, France

3 Department of Forest Ecology and Management, Swedish University of Agricultural Sciences, 90183 Umeå, Sweden

4 EI, Entomologie and Myriapodologie, 522 chemin Saunier, 13690 Graveson, France

5 UAPV UMR 7263 CNRS IRD, Institut Méditerranéen de Biodiversité et Ecologie, 301 rue Baruch de Spinoza, BP21239, 84916 Avignon cedex 09, France
6 Division Forest, Nature and Landscape, Department of Earth and Environmental Sciences, KU Leuven, Celestijnenlaan 200E, Box 2411, 3001 Leuven, Belgium

7 Faculté Des Sciences Et Technologies, CNRS, UR AFPA, University of Lorraine, BP 239, 54504 Vandoeuvre les Nancy Cedex, France

8 Department of Soil Ecology, Helmholtz-Centre for Environmental Research, UFZ, Theodor-Lieser-Straße 4, 06120 Halle (Saale), Germany

9 Department of Biology, University of Leipzig, Johannisallee 21, 04103 Leipzig, Germany

10 Chair of Silviculture, Faculty of Environment and Natural Resources, Univeristy of Freiburg, Tennenbacherstr. 4D, 79085 Freiburg, Germany 


\section{Introduction}

Forests are a major type of ecosystem in Europe, covering $42 \%$ of land surface (Paivinen et al. 2001) and providing a multitude of key ecosystem services, such as timber production, watershed protection and carbon sequestration (Scherer-Lorenzen et al. 2005). These services depend strongly on tree taxonomic richness and on the proportion of different functional type (e.g., evergreen vs. deciduous) in forest stands (Gamfeldt et al. 2013). In addition, tree species richness may determine the abundance and diversity of other groups of organisms (Ampoorter, et al. 2019) that could affect ecosystem processes. Especially, trees shape communities of soil invertebrates, which are key regulators of soil functioning and primary productivity (Wardle 2004; Wall et al. 2012). However, the direct and indirect mechanisms underlying soil invertebrate responses to tree species diversity and composition remain poorly understood, even in temperate forest ecosystems (Korboulewsky et al. 2016).

Trees can influence soil fauna through the provision of energy and matter via living and dead plant products such as leaf and root litter, dead wood, and rhizodeposition. Many soil organisms such as macrodetritivores (earthworms, millipedes, woodlice) feed directly on plant debris (Lavelle and Spain 2001), imposing stoichiometric constraints with lower and narrower carbon to nutrient ratios in animal biomass than that of their feeding resource (Sterner and Elser 2002). Resource nutrient concentrations are therefore particularly important as they determine litter palatability for macrodetritivores, and have important consequences on the structure of their communities, notably on their biomasses (Ott et al. 2014). In mixed forest stands, litter may be of overall higher quality relative to monospecific stands when tree species with high quality litter may compensate for those with low nutrient concentrations or high contents in recalcitrant compounds (e.g., polyphenols or lignin; Korboulewsky et al. 2016). Another pattern often highlighted in the literature is the strong effect of evergreen trees on soil fauna communities (Reich et al. 2005), which can be related to the low litter quality of most evergreen species. Additionally, other evergreen traits such as leaf life span and the phenology of leaf senescence together determine tree canopy properties which affect microhabitats and microclimate conditions at soil surface (Monk 1966).

Beyond litter quality and its consequences for the heterotrophic soil food web, different tree species also vary in a number of physical characteristics that may influence soil fauna communities. For instance, differences in leaf size, leaf shape, and amount of litterfall (including deadwood), determine the total volume of habitats, and their spatial organization for both detritivore and predator species (Aubert et al. 2006, Kaspari and Yanoviak 2009). The structural complexity of litter layers, and the resulting diversity of microhabitats for the soil fauna, also vary from one tree species to another and are likely higher in mixed than pure stands (Hättenschwiler et al. 2005). This may contribute to an increase in abundance, biomass, diversity, and evenness of soil invertebrates in mixed when compared to monospecific forest stands (Hansen and Coleman 1998; Perry and Herms 2016), especially when the mixed stands include deciduous broadleaved trees among evergreen conifers (Kaneko and Salamanca 1999).

The influence of the previously mentioned litter properties (nutrient content, shape, litter layer depth) on soil and forest floor properties and on invertebrate communities also varies with tree canopy richness and composition (Augusto et al. 2002; Ponge 2003). Tree canopy openness is an important but overlooked forest stand characteristic that has important effects on forest floor conditions. By modulating light availability at the soil surface, canopy openness may influence soil communities by altering forest floor microclimate and understory vegetation (Prescott and Vesterdal 2013; Henneron et al. 2015; Mueller et al. 2016). This again can differ depending on tree species richness that can affect canopy openness and litter production through increased canopy packing, as was reported for different European forests (Jucker et al. 2015). In addition, evergreen tree species distinctively affect microclimatic conditions, in particular through a permanent canopy cover, and high leaf area index (LAI) all year round which leads to higher rainfall interception and evaporation and thus drier soils (Augusto et al. 2015).

Characterizing soil fauna responses to the diversity and composition of the standing vegetation is thus complex and often made even more difficult by taxonomic impediments and our lack of knowledge of certain taxa. Indeed, it is difficult if not impossible to obtain rapid and reliable taxonomic assignations at a species level for most of the soil biota (Decaëns 2010). A classic strategy to avoid this problem in soil macrofauna studies is to target assignations to higher taxonomic ranks, which allows the whole community to be considered without prior selection of target taxa (Williams and Gaston 1994; Andersen 1995). Another option is to make species-level identifications possible by restricting the study to a small number of taxa, for which taxonomic expertise is available, that are further assumed to be representative of the whole community or of a particular trophic group thereof. The implication of each of these approaches for our ability to describe community patterns reliably, and the importance of the level of taxonomic resolution they imply, has never been formally addressed with regard to soil fauna. However, it is probable that some of these patterns (e.g., diversity—area, or diversity—available

\section{Springer}


energy relationships) may vary in their shape depending on the fundamental taxonomic units of the study, which could consequently affect observed community responses to environmental gradients (Williams and Gaston 1994; Kaspari 2001; Storch and Šizling 2008).

In this study, we described soil macrofauna communities in forest plots composed of either a single dominant tree species or three co-dominant tree species in four different pedoclimatic zones ranging from boreal to Mediterranean. These plot were part of an existing network of natural forest plots with different tree species richness and composition across Europe (Baeten et al. 2013). We tested three complementary hypotheses. First (H1) higher tree richness in forest stand will promote soil macrofauna richness, diversity, evenness, abundance, and biomass, likely by increasing the probability of including at least one tree species that significantly improve life conditions for invertebrates (e.g., by producing a high quality litter, having a denser canopy that limits microclimatic variations, or promoting more diversified microhabitats in the litter layer). Alternatively, (H2) increasing the proportion of evergreen species will negatively affect detritivore assemblages due to their low-quality litter and soil-acidification effect, but may favor predator organisms by the production of a thicker litter layer and the consecutive provision of more microhabitats. Combined, these expected effects will result in changes in the whole macrofauna community composition. Finally, because of the tighter trophic link between litter characteristics and detritivores species (Scherber et al. 2010; Beugnon et al. 2019), we expect that $(\mathrm{H} 3)$ tree species richness and composition will induce a stronger response in detritivore than in predator communities. These three hypotheses were tested at different levels of taxonomic resolution to assess the response of the whole macrofauna community and of specific groups with narrower ecological niche.

\section{Material and methods}

\section{Study sites and tree stand composition}

The study was carried out within the framework of the SoilForEUROPE project in four forest sites selected to represent four major European forest types along a broad climatic gradient in Europe: thermophilous deciduous forests (Colline Metallifere, Italy), mountainous deciduous forests (Râsça, Romania), temperate mixed coniferous and broadleaf forests (Bialowieza, Poland), and boreal forests (North Karelia, Finland). The sampled plots are part of the FunDivEUROPE exploratory platform (Baeten et al. 2013) excluding within site variation in climate, soil and land use history between plots and specifically designed to disentangle the species diversity and identity effect in the biodiversity—ecosystem functioning relationship (Nadrowski et al. 2010). In each site, replicated forest plots of $30 \times 30 \mathrm{~m}$ were selected to represent either monospecific stands ( 34 plots) or 3 species mixtures (30 plots), further referred to as pure and mixed stands, respectively. Selected tree species (i.e., target species) are 13 locally dominant and representative tree species, including evergreen conifers and evergreen or deciduous broadleaved trees (Table 1). These plots were selected in 2012 during the FunDivEUROPE project and relative basal area of tree species was re-estimated in 2018 for this study. The relative proportion of tree species was based on their relative basal area, and non-targeted species basal area in the plot was kept below 5\%. In each plot we selected three subplots based on tree triplets forming a triangle of three individual trees with a minimal diameter at breast height of $5 \mathrm{~cm}$, composed of either the same target species in the pure stands or the three target tree species in the mixed stands (Fig. S1).

\section{Invertebrates sampling and community descriptors}

Sampling was conducted in 2017 during the phenological spring at each of the four sites. In each plot, soil macrofauna was sampled by excavating one soil block of $25 \times 25 \times 10 \mathrm{~cm}$ within each tree triplet (i.e., three soil blocks per plot). Invertebrates were hand sorted in the field, and immediately fixed and preserved in $70 \%$ ethanol. They were further assigned to broad taxonomic groups (usually orders), with additional consideration of trophic position or ecological categories when relevant. This resulted in 16 groups: Araneae, predatory Coleoptera (Carabidae adults and larvae, Staphylinidae), Opilionidae, Dermaptera, Chilopoda, Blattodea, rhizophagous Coleoptera (larvae of Melolonthinae, Curculionidae, Elateridae), coprophagous Coleoptera (Geotrupinae), endogeic, epigeic, and anecic Lumbricidae, Diplopoda, Isopoda, Diptera larvae, Gastropoda, and Lepidoptera larvae. Species level identifications were done for all Lumbricidae, Isopoda, Diplopoda, Chilopoda, and Araneae specimens. For the few individuals for which this was not possible, genus or family levels were kept for the analysis; as this only concerned a small fraction of specimens, these higher rank taxonomic identifications were treated without distinguishing them from species-level identifications. All invertebrates were counted per broad group or species and weighed individually to the nearest $0.01 \mathrm{mg}$ after gently drying them with a paper towel. The abundance and biomass of the 16 different groups is given in Table S1. We then organized the data into three different matrices: one with the numbers of individuals per plot for each broad group, further referred to as "all macrofauna", and two with the numbers of individuals per plot and per species (or finest level achieved) for the detritivore and predator groups previously mentioned, 
Table 1 Description of the four sample sites, including the tree species pool, and site-specific sampling design

\begin{tabular}{|c|c|c|c|c|}
\hline & Finland & Poland & Romania & Italy \\
\hline \multicolumn{5}{|l|}{ Site description } \\
\hline Latitude, longitude $\left(^{\circ}\right)$ & $62.9,29.9$ & $52.8,23.9$ & $47.3,26.0$ & $43.2,11.2$ \\
\hline $\operatorname{Area}^{\mathrm{a}}\left(\mathrm{km}^{2}\right)$ & 1447 & 346 & 4.26 & 216 \\
\hline Altitude (m) & $139.4 \pm 36.6$ & $165.7 \pm 12.6$ & $891.8 \pm 96.4$ & $405.8 \pm 60.5$ \\
\hline Date of sampling & 2017/06/12-16 & $2017 / 05 / 05-10$ & $2017 / 05 / 22-28$ & 2017/04/10-16 \\
\hline $\operatorname{MAT}\left({ }^{\circ} \mathrm{C}\right)$ & $2.0 \pm 0.3$ & $6.9 \pm 0.1$ & $5.5 \pm 0.5$ & $13.4 \pm 0.3$ \\
\hline MAP (mm) & $632 \pm 6$ & $597 \pm 4$ & $692 \pm 25$ & $738 \pm 43$ \\
\hline Soil type ${ }^{I I}$ & Podzol & Cambisol/Luvisol & Eutric Cambisol & Cambisol \\
\hline Sand $(\%)^{\mathrm{I}}$ & $48.2 \pm 6.2$ & $65.5 \pm 7.5$ & $12.9 \pm 9.4$ & $17.2 \pm 6.4$ \\
\hline Silt $(\%)^{\mathrm{I}}$ & $46.6 \pm 5.6$ & $28.7 \pm 6.3$ & $59.6 \pm 4.9$ & $64.7 \pm 4.9$ \\
\hline Clay $(\%)^{\mathrm{I}}$ & $5.1 \pm 0.8$ & $5.8 \pm 1.6$ & $27.4 \pm 6.1$ & $18.1 \pm 5.4$ \\
\hline $\mathrm{C}\left(\mathrm{mg} \mathrm{g}^{-1} \text { dry soil }\right)^{\mathrm{II}}$ & $37.8 \pm 11.5$ & $28.4 \pm 5.3$ & $49.2 \pm 16$ & $50.4 \pm 13.4$ \\
\hline $\mathrm{N}\left(\mathrm{mg} \mathrm{g}^{-1} \text { dry soil }\right)^{\mathrm{II}}$ & $1.7 \pm 0.6$ & $1.7 \pm 0.2$ & $3.5 \pm 1$ & $2.6 \pm 0.9$ \\
\hline $\mathrm{pH}^{\mathrm{II}}$ & $3.9 \pm 0.3$ & $3.8 \pm 0.3$ & $4.6 \pm 0.7$ & $4.6 \pm 1.1$ \\
\hline Bulk density $\left(\mathrm{g} \mathrm{cm}^{-3}\right)^{\mathrm{II}}$ & $1.03 \pm 0.09$ & $1.02 \pm 0.0$ & $0.93 \pm 0.06$ & $0.88 \pm 0.07$ \\
\hline $\begin{array}{l}\text { Number of mono-specific } \\
\text { plots }\end{array}$ & 6 & 6 & 8 & 10 \\
\hline Number of mixed plots & 3 & & 8 & 9 \\
\hline \multicolumn{5}{|l|}{ Tree species pool } \\
\hline (1) Abies alba & & & $\times$ & \\
\hline (1) Picea abies & $x$ & $\times$ & $\times$ & \\
\hline \multicolumn{5}{|l|}{ (1) Pinus sylvestris } \\
\hline (2) Quercus ilex & & & & $x$ \\
\hline (3) Acer pseudoplatanus & & & $\times$ & \\
\hline (3) Betula pendula/pube & & $x$ & & \\
\hline (3) Carpinus betulus & & $x$ & & \\
\hline (3) Castanea sativa & & & & $\times$ \\
\hline (3) Fagus sylvatica & & & $\times$ & \\
\hline (3) Ostrya carpinifolia & & & & $\times$ \\
\hline (3) Quercus petraea & & & & $x$ \\
\hline (3) Quercus robur & & $x$ & & \\
\hline (3) Quercus cerris & & & & $\times$ \\
\hline
\end{tabular}

Soil measurements are from the first $10 \mathrm{~cm}$ of mineral soil. (1) Evergreen needle-leaf, (2) evergreen broadleaf, (3) deciduous broadleaf

$M A T$ mean annual temperature, MAP mean annual precipitation, from WorldClim

${ }^{a}$ Area was obtained from the polygon area joining most distant plots within each country, using Google Earth

${ }^{\text {I } D a t a ~ f r o m ~ S o i l F o r E U R O P E ~ p r o j e c t ~}$

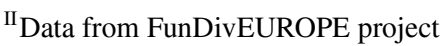

further referred to as "detritivore assemblage" and "predator assemblage", respectively (taxa list in Table S2).

From these three matrices, we calculated several community descriptors: taxonomic richness $(S)$ Pielou's evenness $(J$; Pielou 1966), and Hill ${ }_{q=l}$ diversity $\left(D_{1}\right) . D_{1}$ was obtained with the formula:

$D_{q}=\left(\sum_{i=1}^{S} p_{i}^{q}\right)^{\frac{1}{1-q}}$ where $S$ is the total number of taxa (i.e., fundamental taxonomic units: broad groups or species depending on the matrix), $p$ the proportion of taxa $i$ and $q$ the "order" of the diversity. The order $q$ determines the diversity index sensitivity to common and rare taxa with values of $q$ below or above one giving diversities highly sensitive to rare or common taxa, respectively (Jost 2006). We choose $q=1$ and even though Eq. (1) is not defined when the diversity order is one its limit exists and equals:

\begin{tabular}{|l|l|l|l|l|}
\hline Journal : Large 442 & Article No : 4931 & Pages : 13 & MS Code : 4931 & Dispatch : 1-5-2021 \\
\hline
\end{tabular}


247

$D_{1}=\exp \left(-\sum_{i=1}^{S} p_{i} \ln p_{i}\right)=\exp (H)$

248

249

250

251

252

253

254

255

256
This is the exponential of Shannon entropy which has the advantage of being relatively insensitive to rare or common taxa. All analyses were done using R software v.3.5.2 (R Core Team 2019) with the individual forest plots as replication units (i.e., the three samples per plot were pooled for calculations). Community descriptors were calculated with the diversity function of the vegan package (Oksanen et al. 2019).

\section{Selection of predictor variables}

The predictor variables used in this study are summarized in Table S3, and protocols of variable acquisition are detailed in Online Appendix 1. Tree richness was included in the analyses as a factor (one or three tree species), and we assessed the effect of tree functional type using the relative basal area of evergreen species across the three tree triplets. Other predictor variables (i.e., leaf litter traits, microenvironmental characteristics, and soil properties) were summarized by computing three Principal Components Analysis (PCA) ordinations (Fig. S2) with the prcomp function from the package factoextra (Kassambara 2019). The scores of the forest plots on the retained axes of each PCA were then used as synthetic environmental variables to further explain the structure and composition of macrofauna communities. Pearson correlation between all predictor variable is given in Figure S3.

Litter traits included the concentrations of cellulose, lignin, polyphenols, nitrogen, and calcium measured in freshly fallen leaf litter of all tree species for each country independently (i.e., we used country mean trait value for each tree species). PCA was computed with community weighted means of these traits (Garnier et al. 2004), using tree basal area over the three triplets as a measure of the relative proportion of each species. We kept the first PCA axis which accounted for $49.5 \%$ of overall variance and represented a "litter quality" gradient from low-quality associated with high concentrations of lignin and cellulose (negative scores) to high-quality associated with high nitrogen and polyphenol concentrations (positive scores) (Fig. S2A).

The microenvironmental variables included forest floor mass, biomass of understory vegetation and volume of coarse deadwood debris per unit ground area, and the leaf area index of canopy trees as a proxy of canopy closure. Here, to include enough variance in microhabitat and microclimate properties, we kept the first two PCA axes, explaining $38.2 \%$ and $26 \%$ of the overall variance, respectively. The first axis corresponded to a switch from plots with a high understory vegetation biomass (negative scores), to plots with most of the soil covered by a thick forest floor (positive scores), and is for simplicity further referred to as "forest floor mass". The second axis reflected "canopy openness", with closed canopy plots having negative scores on this axis (Fig. S2B).

Soil characteristics in the top $10 \mathrm{~cm}$ of mineral horizon included bulk density, $\mathrm{pH}$ (determined in a $\mathrm{CaCl}_{2}$ solution), clay content, carbon content, and $\mathrm{C} / \mathrm{N}$ ratio. We kept the first axis which explained $52.5 \%$ of the overall variance and represented a gradient of "soil quality", with sites having negative scores being characterized by more compact, acidic and C-poor soils (Fig. S2C).

\section{Statistical analysis}

To test the effect of tree stand properties and environmental variables on the whole macrofauna, detritivore, and predator community composition, we calculated the Bray-Curtis dissimilarity matrix of the three matrices and performed a partial distance-based Redundancy Analysis (dbRDA; Legendre and Anderson 1999) with capscale function of the vegan package, and including the country as a random factor with the argument condition (Borcard et al. 2018). The significance of the predictor variable and of the ordination along each axis was assessed using permutation tests (anova function of the stats package, R Core Team 2019), constraining the permutation within countries (4999 permutations, how function in permute package; Besag and Clifford 1989).

Since macrofauna communities are concomitantly influenced by many environmental factors, themselves driven by tree species richness and functional type, we modeled the response of each community descriptor first with a model (M1) including only tree species richness and functional type as co-variable, and then with a complete model (M2) including also microenvironment variable. Thus, $\mathrm{H} 1$ and $\mathrm{H} 2$ are validated if a significant effect of tree species richness and evergreen proportion are detected in M1, respectively. If these effects are no longer supported in M2 and are replaced by significant effects of the other co-variables, this gives further insights into the mechanisms through which tree species richness and evergreen proportion affect macrofauna communities. On the other hand, similar results in M1 and M2 would suggest that tree species richness or evergreen proportion effects are mediated by mechanisms others than those covered by our co-variables. Finally, the fact of finding significant effects only for microenvironmental variables in M2, would imply that macrofauna communities are influenced by microenvironment independently of tree species richness and evergreen proportion. $\mathrm{H} 3$ was tested by comparing the results of both models obtained for detritivore and predator assemblages separately.

We applied a MultiModel Inference (MMI) approach (Burnham et al. 2002) allowing to quantify for the relative 
importance of each co-variable and constructed the two consecutive models as below:

$\mathrm{Y} \sim$ Tree SR + Evergreen $\%+1 \mid$ Country

$\mathrm{Y} \sim$ Tree SR + Evergreen $\%+$ Litter quality + FF mass + Canopy openness + Soil quality + 1|Country

\section{Results}

We collected a total of 2951 soil invertebrates belonging to 16 broad groups, with an average of $237.6 \pm 98.9$ indi- where $Y$ is one of the 15 response variables (i.e., taxonomic richness, Hill ${ }_{\mathrm{q}=1}$ diversity, evenness, abundance, and biomass calculated separately for the whole macrofauna and detritivore and predator assemblages). The list of terms preceded by the " " are the explanatory variables (with Tree $\mathrm{SR}=$ tree species richness; Evergreen $\%=$ percentage of evergreen basal area; litter quality $=\mathrm{PC} 1$ of litter traits; $\mathrm{FF}$ mass $=\mathrm{PC} 1$ of microenvironmental variables; canopy openness $=$ PC2 of microenvironmental variables; soil quality $=$ PC1 of soil properties; PC refereeing to the plot score on the axes of PCA of environmental variables as defined in the previous section), and "1ICountry" refers to the belonging to countries included as random factor. We used Generalized Linear Mixed Models with the $\operatorname{glmm} T M B$ function of the glmmTMB package (Magnusson et al. 2019) and checked for residual normality and homoscedasticity. Abundance data were $\log (1+x)$ transformed since including an argument to model residuals distributions in the function (Poisson or negative binomial family) was not sufficient to meet model assumptions (Ives 2015). In both model steps (M1 and M2), best models were selected based on the Akaike Information Criterion for small sample size (AICc, dredge function in the $M u M I N$ package), keeping all models within $\Delta \mathrm{AICc}<6$ (Harrison et al. 2018). Predictor estimates were obtained by averaging their value across the models in which the predictor appeared to avoid estimate value shrinkage towards zero (Harrison et al. 2018). Estimates were standardized ( $\beta_{\text {st }}$ scale-standardization) to allow cross model comparisons of predictor effects. To quantify to what extent including microenvironmental variables improve community descriptors modeling, we compared the best model obtained from the reduced (M1) and complete (M2) model. These two best models were compared on the basis of the additional variance explained by fixed effects $\left(R^{2} \mathrm{~m}\right)$ and by fixed and random effects ( $R^{2}$ c; Nakagawa and Schielzeth 2013), and AICc. Additionally to this first analysis across the four sites (continental scale), we performed the same analytical procedure with the complete model (M2) in each country individually (regional scale) to investigate to what extent the observed effects could depend on the geographic context (as in de Wandeler et al. 2018). Abundance data were $\log (1+x)$ transformed as well as detritivore and predator biomass data to reach model assumptions. The analysis was not feasible for detritivore assemblage in Finland because of the large proportion of empty sites (eight out of nine plots). viduals per square meter in Finland, 246.1 \pm 106 in Poland, $300 \pm 111.8$ in Romania, and 204.1 \pm 76.4 in Italy. Among the identified specimens, roughly one sixth of all individuals collected (504 individuals) were detritivores assigned to 14 species of Lumbricidae, 10 of Isopoda, and 20 of Diplopoda, and a bit more than one fourth (803 individuals) were predators assigned to 90 species of Araneae and 49 of Chilopoda. Nine detritivore species were singletons (1 individual sampled), and 3 doubletons ( 2 individuals sampled), while 55 singletons and 25 doubletons predator species were recorded. Macrofauna individuals were sampled in every plots, but detritivore species (Lumbricidae, Isopoda, Diplopoda) were absent in nine plots, mainly in Finland (absent in eight over nine plots).

\section{Community composition}

At a coarse level of taxonomic resolution, whole macrofauna communities were organized along the first axis of the dbRDA (Fig. 1), which explained $38.4 \%$ of overall variance $(p<0.001$, Table S4) and was mainly driven by litter quality, evergreen proportion, and forest floor mass. Plots with negative scores on the first axis were characterized by high understory biomass, thin forest floor layer, high litter chemical quality, and low evergreen proportion, and they supported high abundance of earthworms of all three ecological types (i.e., endogeic, epigeic, and anecic). Plots with positive scores were dominated by evergreen tree species, presented a thick forest floor layer, a high amount of coarse deadwood debris, and harbored a relatively high abundance of predators (Araneae, Chilopoda, predatory Coleoptera, Opiliones). The second axis explained $23.4 \%$ of overall variance $(p=0.075)$ and highlighted the effect of soil quality on macrofauna communities. Plots with positive scores were characterized by low clay and carbon content, lower $\mathrm{pH}$ associated with evergreen tree dominance, and harbored comparatively higher densities of rhizophagous Coleoptera, Diptera larvae, and Diplopoda. The same analysis on detritivore and predator assemblages did not reveal any significant ordination ( $\mathrm{dbRDA}_{\text {Detritivore }}$ axis $1 p=0.13$, dbRDA $_{\text {Predator }}$ Axis $1 p=0.06$, Fig. S4, Table S4), meaning that the predictors considered in our study did not significantly explain community composition at the finer level of taxonomic resolution. 


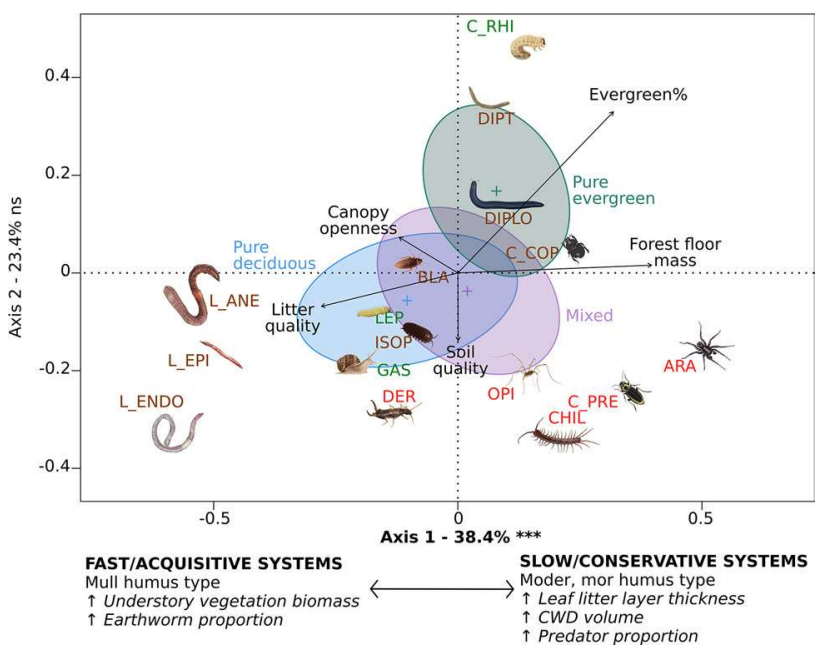

Fig. 1 dbRDA biplot of the whole macrofauna community. ARA Araneae, $C \_P R E$ Coleoptera Predaceous, $C \_R H I$ Coleoptera Rhizophagous, GAS Gasteropoda, CHIL Chilopoda, L Lumbricidae, EPI Epigeic, ANE Anecic, ENDO Endogeic, DIPLO Diplopoda, ISOP Isopoda, OPI Opilionidae, DER Dermaptera, BLA Blattaria, LEP Lepidotera Larvae, DIPT Diptera Larvae, $C W D$ coarse deadwood debris. Name colors represent predaceous (red), saprophagous (brown), and herbivorous (light green) groups. Solid black arrows represent significant predictor variables after permutational ANOVA. Explained variance (\%) and level of significance of each axis is shown in the axis title. Ellipses correspond to forest systems levels: pure deciduous (light blue), mixed (purple), and pure evergreen (dark green) stands. Illustration credit www.lesbullesdemo.fr

\section{Community structure}

When all macrofauna was considered, the proportion of explained variance by fixed effects $\left(R^{2} \mathrm{~m}\right)$ in the full model (M2) varied from $14 \%$ (abundance) to $44 \%$ (Hill ${ }_{q=l}$ ' diversity $\left.D_{1}\right)$. Accounting for random effects $\left(R^{2} \mathrm{c}\right)$ increased the proportion of explained variance to $24 \%$ (evenness $J$ ) and to $76 \%$ (biomass), indicating a strong variability between countries. Broad group richness, Hill ${ }_{q=1}$ diversity and evenness were well predicted in the reduced model (M1), while biomass, and to a lesser extent abundance, were better predicted in the complete model (M2). Broad group richness, Hill $_{q=1}$ diversity and evenness were higher in mixed than in monospecific stands (M1, $S$ : std.est. $=0.51, p=0.013 ; D_{1}$ : std.est. $=0.72, p<0.001 ; J$ : std.est. $=0.62, p<0.01$, Fig. 2 , Fig. S5-S6), and at the same time decreased with the proportion of evergreen trees (M1, S: std.est. $=-0.46, p<0.001$; $D_{1}$ : std.est. $=-0.50, p<0.001 ; J$ : std.est. $=-0.36, p<0.01$, Fig. 2, Fig. S5-S6). There were no consequent changes between M1 and M2 in the proportion of explained variance or AICc, except for broad groups $\mathrm{D}_{1}$ that also decreased with canopy openness $\left(\Delta \mathrm{AICc}=-9.5, \Delta R^{2} \mathrm{~m}=+0.06 \%\right.$, $\Delta R^{2} \mathrm{c}=+0.04 \%$; Fig. 2, Table S5). Broad group abundance was poorly predicted regardless of the model, while biomass decreased with evergreen proportion in M1. However, this effect disappeared in M2, where total biomass instead decreased with forest floor mass and increased with canopy openness (Fig. 2). In this case, the best complete model showed a lower AICc $(\triangle \mathrm{AICc}=-9.5)$ and higher proportion of explained variance $\left(\Delta R^{2} \mathrm{~m}=+0.08 \%, \Delta R^{2} \mathrm{c}=+0.24 \%\right.$; Fig. 2, Table S5). Most significant effects detected at the continental scale were also detected in at least 1 country (14 effects out of 23; Table S6). Only the negative effect of canopy openness on broad group Hill ${ }_{q=1}$ diversity and the negative effect of evergreen proportion and broad group evenness only appeared at the continental scale. On the other hand, some factors that were not significant at the continental scale showed significant effects at the regional scale in one or two countries. Regarding detritivore species assemblages, the proportion of variance explained by fixed effects was low, ranging from $4 \%(J)$ to $23 \%$ (biomass). Including the country as a random factor substantially increased the explained variance to $68 \%(J)$ and $79 \%$ (abundance), except for taxa Hill ${ }_{q=I}$ ' diversity which only reached $24 \%$ of total explained variance in both models. In M1, none of the community metrics were affected by tree species richness, while evergreen proportion negatively affected all of them (Fig. 2, Table S5). However, most of these effects were replaced in M2 by the effect of microenvironmental variables, which produced a better model with substantially lower AICc and higher explained variance. Detritivore richness marginally increased with canopy openness, while detritivore Hill $_{q=I}{ }^{\prime}$ diversity increased with litter quality (std.est. $=0.33$, $p=0.029$ ). Evergreen proportion was retained as the best predictor of detritivore evenness in both models (M1: std. est. $=-0.22, p=0.012 ; \mathrm{M} 2$ : std.est. $=-0.21, p=0.033$; Fig. 2, Table S5). Forest floor mass was negatively correlated with abundance and biomass (ab: std.est. $=-0.08$, $p=0.013 ; m$ : std.est. $=-0.17, p<0.001 ;$ Fig. 2 , Table S5), while the opposite pattern was found with canopy openness (ab: std.est. $=0.15, p=0.023 ; m$ : std.est. $=0.22, p=0.02$; Fig. 2, Table S5). Five out of the eight significant relationships found at the continental scale were also observed at the regional scale, but the effect of forest floor mass and canopy openness on detritivore abundance and biomass mainly occurred at the continental scale. In Poland, tree SR increased detritivore Hill ${ }_{q=1}$ diversity, and evergreen proportion reduced detritivore biomass and marginally abundance.

Most descriptors of predator assemblages were well explained by fixed factor, except for evenness, with $R^{2} \mathrm{~m}$ ranging from $9 \%$ (biomass) to $45 \%\left(D_{1}\right)$. The random factor accounted for a very small part of predator richness, diversity, or evenness, but consistently increased explained variance for abundance and biomass. Most of community metrics were better predicted in the complete model. Predator species richness and (marginally) Hill's diversity decreased with litter quality $\left(S\right.$ : std.est. $=-0.29, p=0.012 ; D_{1}$ : std. est. $=-0.21, p=0.059)$ and strongly increased with canopy 
Fig. 2 Standardized estimates and explained variance from Multimodel Inference. Circle size and colour intensity are proportional to the effects trengh, red colour show for negative effect, blue colour show positive effect). The level of significance of the effect is indicated $(\dagger, *, * *, * * *$ : $p$ val ue $<0.1,<0.05,<0.01,<0.0$ $01)$. Non-significant variable estimates are not shown but are reported in Table S5. The bar graph on the right indicates the change in the proportion of variance explained by fixed effects $\left(R^{2} \mathrm{~m}\right.$, light green $)$ and fixed plus random effects $\left(\Delta R^{2} \mathrm{c}\right.$, dark green), as well as the difference in $\mathrm{AICc}(\triangle \mathrm{AICc}$, number) between the most parcimonious models from each of the two hypotheses. Tree $S R$ tree species richness, FF mass forest floor mass, Canopy open. canopy openness

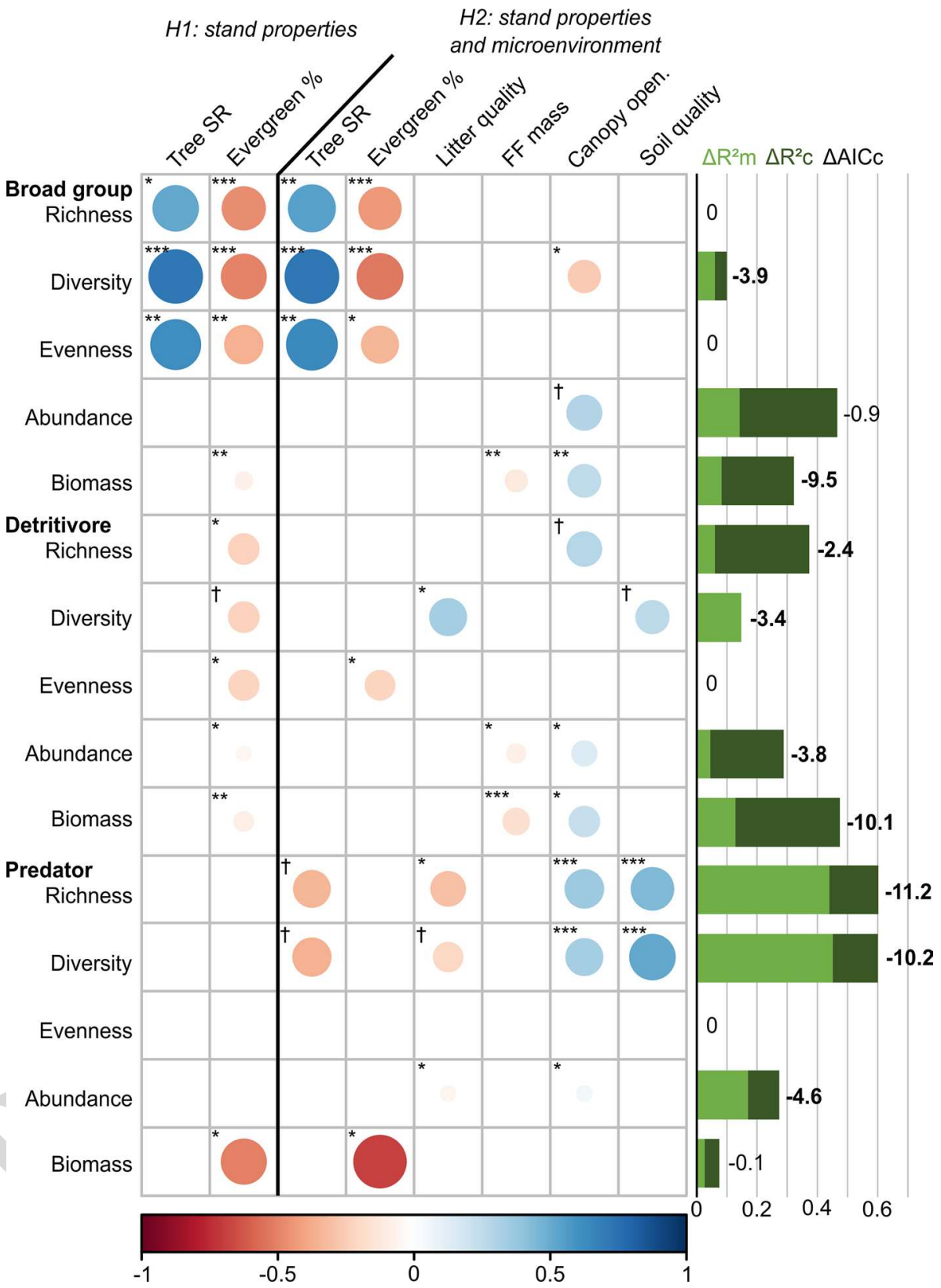

openness $\left(S\right.$ : std.est. $=0.36, p<0.001 ; D_{1}$ : std.est. $=0.33$, $p<0.001)$ and soil quality $(S$ : std.est. $=0.45, p<0.001$; $D_{1}$ : std.est. $\left.=0.51, p<0.001\right)$. Here, changes in the proportion of explained variance and AICc were very high $(S$ : $\Delta R^{2} \mathrm{~m}=+0.44 \%, \Delta R^{2} \mathrm{c}=+0.16 \%, \Delta \mathrm{AICc}=-11.2 ; S:$ $\Delta R^{2} \mathrm{~m}=+0.45 \%, \Delta R^{2} \mathrm{c}=+0.15 \%, \Delta \mathrm{AICc}=-10.2 ;$ Fig. 2 , Table S5). Predator abundance weakly decreased with litter quality and weakly increased with canopy openness, while biomass strongly decreased with evergreen proportion in both the reduced and complete models. Nine of the 11 significant effects detected at the continental scale were also present at the regional scale. Tree SR decreased predator abundance in Finland but increased their biomass in Poland. Canopy openness negatively affected predator assemblage evenness in both Poland and Italy, while litter quality decreased predator biomass in Finland and Poland. Finally, soil quality had a negative effect on predator abundance and biomass in Finland, while FF mass increased predator abundance in Poland.

\section{Discussion}

The results of our study show the effect of tree richness and functional type (i.e., stand evergreen proportion) on soil macrofauna communities and highlight the underlying mechanisms. Interestingly, we found that forest stands with a low evergreen tree proportion supported macrofauna

\begin{tabular}{|l|l|l|l|l|}
\hline Journal $:$ Large 442 & Article No : 4931 & Pages : 13 & MS Code : 4931 & Dispatch : 1-5-2021 \\
\hline
\end{tabular}


communities with a higher number of broad groups that were also more diverse and evenly represented. In contrast, at a species-level taxonomic resolution, the effects of tree species richness and functional type were less pronounced. Instead, litter quality, microhabitat and microclimate became important drivers of both detritivore and predator assemblage structure, with trophic cascade effects potentially occurring between these two trophic groups. The majority of the effects observed at the continental scale were also present in at least one country, giving further support to our results (Table S6). Some effects idiosyncratically disappeared or appeared at the regional scale due to changes in sample size, or narrower environmental and community variable gradients as reported for earthworms in European forests (de Wandeler et al. 2018). In our study, considering this regional scale provided no additional insights into the links between macrofauna communities and their environment, and this will therefore not be discussed further.

\section{Main axes of variability in soil macrofauna communities}

The results of our redundancy analysis show that as much as $38.4 \%$ of the total variability in macrofauna communities, when described at a coarse taxonomic resolution, was explained by an opposition between two extremes of a gradient from pure deciduous to pure evergreen stands. This gradient is consistent with the classification of ecosystems along a productivity gradient (Wardle 2004), soil process domains (Desie et al. 2019), or the distinction between different humus types ranging from mull, i.e., "fast turnover" and "acquisitive strategy", to moder and mor, i.e., "slow turnover" and "conservative strategy" (Ponge 2003; Zanella et al. 2011).

In fast cycling systems, deciduous trees provide highquality litter and canopy openness over the year, allowing the establishment of an important understory vegetation, which produces litter rich in important nutrients such as calcium and nitrogen (Reich et al. 2005; Gilliam 2007; Augusto et al. 2015). This results in both a higher earthworm proportion in macrofauna communities and more diverse detritivore assemblages in general (Reich et al. 2005). Being more abundant and diverse, macrodetritivores are expected to further accelerate litter burial and decomposition, thus reducing the litter layer thickness at the soil surface (Hedde et al. 2010; Coulis et al. 2016). Conversely, the decrease in earthworm relative abundance and detritivore diversity in evergreen dominated forests is a long known pattern that can be explained by the poor quality of litter inputs as well as the more acidic conditions of the forest floor (Reich et al. 2005; Ammer et al. 2006; Schelfhout et al. 2017). Such a decrease in macrodetritivore abundance is expected to be associated to lower bacterial activity, thicker forest floor layer, and the promotion of other groups of smaller detritivores such as Collembola (Scheu et al. 2003). This probably also explains the observed increase in predator relative abundance in stands with higher evergreen proportion, as this group could benefit simultaneously from the higher diversity and amount of microhabitats, and from the increased availability of mesofauna prey (Arpin et al. 1986; Kaspari and Yanoviak 2009).

\section{Tree diversity and functional type direct versus indirect effects}

In line with our first hypothesis, both our reduced and complete model showed a strong positive effect of tree species richness and a negative effect of evergreen proportion on the richness, diversity, and evenness of macrofauna broad $\mathbf{A 0 5}$ groups. This is globally congruent with the results of other studies that described a higher diversity of soil organisms at a broad taxonomic level in mixed compared to pure evergreen forests (Scheu et al. 2003; Salamon et al. 2008). As mentioned previously, many environmental factors can differ between mixed and pure forests, including litter quality and trait diversity, microhabitat heterogeneity and quantity, canopy openness and soil quality (Scherer-Lorenzen et al. 2005), and most of them could indirectly explain tree effects on soil macrofauna communities. However, when included in a more detailed statistical model, none of the microenvironmental variables considered in our study were found to explain macrofauna community metrics at a broad level of taxonomic resolution, apart from canopy openness which had a weak negative effect on Hill ${ }_{q=1}$ diversity. This suggests that tree species richness and evergreen proportion effects on macrofauna broad groups could be related to other microenvironmental variables not included in our analysis, such as litter trait diversity or microhabitat heterogeneity. This would be in line with other studies that have emphasized the importance of litter chemical and physical trait variation, which may both determine resource diversity for detritivores and microhabitat quantity and diversity for invertebrates in general (Hansen and Coleman 1998).

At a finer level of taxonomic resolution, tree species richness no longer had a detectable effect on detritivore nor $\mathbf{A Q 6}$ predator community descriptors, as indicated by our reduced model. Concomitantly, the negative effect of evergreen proportion on detritivore and predator assemblages produced by the reduced model was not retained in the complete model, except for detritivore evenness and predator biomass. Instead, our results revealed rather an indirect effect via resource quality, habitat volume, and microclimate. The lack of tree species richness effect on macrofauna assemblages at this level of taxonomic resolution, is congruent with similar studies focusing on earthworms or on detritivorous and predatory beetles (Schwarz et al. 2015; Chamagne et al. 
2016; De Wandeler et al. 2018). Other studies did report a positive effect of tree species richness on spiders, saproxylic beetles, or earthworm richness, but differences in sampling protocols and study design can probably explain these apparently contradictory results (Chamagne et al. 2016; Ampoorter et al. 2019). Here, we also have to consider that our design only included two levels of tree species richness (monocultures and three-species mixtures), which is different from a true species richness gradient. This might have impeded the detection of a tree richness effect, if it occurs at another level of the diversity gradient. The negative effect of evergreen proportion on detritivore evenness was consistent regardless of the model, suggesting a significant importance of diversity of litter traits or microhabitat, as already discussed for broad group diversity. The negative response of predator biomass to evergreen proportion, which was also highlighted by both modeling approaches, and the simultaneous lack of effect on their abundance, indicates that evergreen trees drive the predator assemblages towards smaller body-sized taxa in less productive stands (Sklodowski 2002). This supports the previously discussed idea that soil fauna communities in evergreen-dominated stands are dominated by small detritivores (Collembola and Acari), representing a preferred prey for small body-sized predators (Arpin et al. 1986; Scheu et al. 2003).

Detritivore and predator communities also showed a strong response to canopy openness, with increased detritivore abundance and biomass and predator richness and diversity in more open forests. This can first be explained by the direct controls exerted by canopy openness on forest ground insolation, water availability, and temperature conditions (Prescott 2002), as well as their expected effects on ectotherm activity and on animals' ability to access resources (Turner et al. 1987; Kaspari et al. 2000; Salmon et al. 2008). Secondly, canopy openness increase light and water availability for understory plants, which can result in higher plant cover and diversity (Thomas et al. 1999). Detritivores will thus benefit from the nutrient-rich herbaceous plant leaf litter and roots, which may constitute an important and high-quality source of organic matter (Lavelle and Spain 2001; Gilliam 2007; Henneron et al. 2015). Finally, predators may also rely on understory vegetation which determines to a large extent the characteristics and heterogeneity of their microhabitat (Pakeman and Stockan 2014).

\section{Detritivore versus predator responses}

A surprising result of our study is the fact that predator assemblages seem to be more sensitive to soil quality than detritivores. This predator response to soil quality may first be attributed to the fact that roughly half of them belonged to Chilopoda in our samples (Table S2), a group which is known to have at least partly endogeic behavior and is therefore sensitive to soil properties, notably soil $\mathrm{pH}$ and organic matter content (Blackburn et al. 2002). Conversely, the absence of detritivore response may be explained by three mechanisms. First, it is possible that other soil and forest floor properties not included here, such as forest floor $\mathrm{pH}$ or litter phosphorus content, may be more important for detritivore communities (De Wandeler et al. 2016). Secondly, detritivore assemblages were composed of both endogeic groups (endogeic Lumbricidae) and epigeic groups (epigeic Lumbricidae, Diplopoda, and Isopoda). Epigeic taxa may show weaker response to soil characteristics than endogeic taxa which may have resulted in the absence of response (Scheu and Falca 2000; Henneron et al. 2015; De Wandeler et al. 2016). Finally, soil characteristics and plot scores on the first PCA axis were strongly country specific (Table 1), and it is possible that by including country as a random factor in the models, captured part of soil characteristics variations was obscured. This is supported by the smaller proportion of variance explained by fixed compared to random effects (14 vs $50 \%$ on average) for detritivore assemblage descriptors, which is notably due to the very low abundance of these organisms in Finland.

In addition to the direct and indirect effects of tree richness and functional type on macrofauna communities, trophic cascades may also have occurred between detritivore and predator assemblages, particularly because Lumbricidae, and to a lesser extent Diplopoda and Isopoda, represent potentially important preys for Chilopoda and Araneae (Scheu and Falca 2000). First, higher detritivore abundance and biomass in response to increased canopy openness may have enhanced predator diversity and richness through higher resource availability (Abrams 1995). Secondly, increased detritivore diversity in response to litter quality may have resulted in a more heterogeneous resource for predators, potentially decreasing prey-finding probability for the more specialized species (Root 1973), and resulting in the observed less rich, diverse and abundant predator assemblages. These mechanisms stress the importance of including trophic interactions when modeling soil macrofauna distribution in forests (Scheu et al. 2003; Salamon et al. 2008). To this end, it would also be interesting to include in future studies other sampling methods, such as pitfall traps, that could be more effective at sampling large, mobile predators such as Carabidae that may feed on large Lumbricidae.

\section{Importance of taxonomic resolution}

Given that the effect of tree species richness and evergreen proportion was detectable on whole macrofauna communities described at a low taxonomic resolution but no longer on detritivore or predator assemblages identified at the species level deserves particular attention. 
Mixed deciduous-evergreen stands, with their intermediate position between two forest type extremes ("fast" pure deciduous, versus "slow" pure evergreen systems) may provide the necessary conditions for the co-existence of a high number of broad groups with contrasting ecological requirements (Fig. 1). This can also be explained by the fact, as mentioned previously, that mixed deciduousevergreen forests produce a litter layer with larger chemical and physical trait variation, thus increasing resource diversity for detritivores and microhabitat features for invertebrates in general (Schuldt et al. 2008). The same does not apply when considering individual detritivore or predator species, because their narrower environmental preferences limit them to a more restricted part of the environmental gradient. This can explain why, at the species level, detritivores and predators were more sensitive to resources, habitat, and microclimate conditions than to tree species diversity and functional type (Fig. S4; Kaspari 2001).

The differences in response patterns highlighted by the use of different levels of taxonomic resolution also illustrate some important methodological issues. Indeed, approaches at low taxonomic resolution are often favored in studies of soil macrofauna, especially because they allow to bypass the taxonomic impediment that exists for many groups of soil invertebrates (Decaëns et al. 2010). The use of broad taxonomic levels makes it possible to consider the whole macrofauna community without reducing datasets to the best-known groups for which species-level identifications are possible. Taxa of higher rank also have wider geographic distributions, making comparisons easier between geographically distant sites. In our case, where sites harbor contrasting macrofauna species pools, the multiple pedoclimatic changes along latitude may be the major drivers of soil communities (De Wandeler et al. 2018). This is supported by the fact that the proportion of variance explained by random effects is larger when using species than when using broad group as fundamental taxonomic units (Table S5), as well as the small effect of the included predictor variables on detritivore and predator assemblage composition in the dbRDA analysis (Table S4, Fig. S4). Finally, datasets constructed at coarse levels of taxonomic resolution also by definition have fewer zeros than those constructed at species level, thus increasing the robustness and statistical power of analyses (Harrison et al. 2018). However, a corollary of this is that they are also potentially less efficient at detecting subtle community responses to ecological gradients since the distributions of higher rank taxa along these gradients are wider than those of the species that constitute them (Kaspari 2001). This stresses the importance of investigating community responses at different levels of taxonomic resolution.

\section{Conclusion}

Our study highlights the complexity of the direct and indirect mechanisms underlying the relationships between tree species richness and composition and macrofauna communities. Mixed forest stands supported richer, more diverse and even macrofauna communities, at a broad level of taxonomic resolution. Compared to mixed stands, pure deciduous stands favored Lumbricidae and other macrodetritivore groups, while evergreen forests were dominated by predator taxa. Combined, these two results suggest that mixed forest stands offer resource, microhabitat, microclimate, and soil conditions suitable for a wide range of organisms of contrasting lifestyles. Future studies should incorporate if possible quantitative description of changes in litter or fine root trait diversity and habitat heterogeneity, as they can be of importance for soil macrofauna. Macrofauna response to tree species richness and functional type was detectable almost only at a coarse level of taxonomic resolution, while macrofauna species rather responded to microenvironmental variables. This highlights the importance of combining different levels of taxonomic resolution to elucidate in a comprehensive way the complex tree-macrofauna relationships in forest ecosystems.

Supplementary Information The online version contains supplementary material available at https://doi.org/10.1007/s00442-021-04931-w.

Acknowledgements This research was part of the SoilForEUROPE project funded through the 2015-2016 BiodivERsA COFUND call for research proposals, with the national funders Agence Nationale de la Recherche (ANR, France), Belgian Science Policy Office (BELSPO, Belgium), Deutsche Forschungsgemeinschaft (DFG, Germany), Research Foundation Flanders (FWO, Belgium), and The Swedish Research Council (FORMAS, Sweden). We thank the site managers Leena Finér with the Finnish Forest Research Institute (Metla), Bogdan Jaroszewicz with the University of Warsaw, Olivier Bouriaud with the Forest Research and Management Institute (ICAS), and Filippo Bussotti with University of Florence and associates, as well as the SoilForEUROPE consortium for their assistance with the soil sampling campaign (project website: https://websie.cefe.cnrs.fr/soilforeurope/). The authors thank Sylvain Coq, Alexandru Milcu, Marion Blache and Fiona Cornet for their precious help during the sampling campaign and lab analysis and Morgane Arietta Ganault for illustrations. We thank the two anonymous reviewers whose constructive comments improved the manuscript. This work was possible thanks to the grant awarded to Pierre Ganault from the "Ecole Doctorale GAIA" of the University of Montpellier.

Author contribution statement $\mathrm{SH}, \mathrm{BM}, \mathrm{JN}, \mathrm{TD}$ participated in designing the sampling campaign, JW, LMG, LPDS, JN, SH, JFD, BM, TD participated in the sampling campaign, PG, JFD, EI, AP, CM and TD did the species identification and laboratory analysis, PG analyzed the data, PG and TD wrote the manuscript, all co-authors contributed in the writing of the manuscript.

Data availability The datasets generated during and/or analyzed during the current study will be used for a data paper and then uploaded to the 
FunDivEUROPE data platform https://fundiv.befdata.biow.uni-leipz ig.de/data.

\section{References}

Abrams PA (1995) Monotonic or unimodal diversity-productivity gradients: what does competition theory predict? Ecology 76:20192027. https://doi.org/10.2307/1941677

Ammer S et al (2006) Factors influencing the distribution and abundance of earthworm communities in pure and converted Scots pine stands. Appl Soil Ecol 33:10-21. https://doi.org/10.1016/j. apsoil.2005.09.005

Ampoorter E, Barvaro L et al (2019) Tree diversity is key for promoting the diversity and abundance of forest-associated taxa in Europe. Oikos 129:133-146. https://doi.org/10.1111/oik.06290

Arpin P et al (1986) Influence du peuplement forestier sur la faune et la microflore du sol et des humus, description des stations et étude de la faune du sol. Revue D'ecologie Et De Biologie Du Sol 23:89-118

Augusto L, Ranger J, Binkley D, Rothe A (2002) Impact of several common tree species of European temperate forests on soil fertility. Ann for Sci 59:233-253. https://doi.org/10.1051/forest:20020 20

Augusto L, De Schrijver A, Vesterdal L et al (2015) Influences of evergreen gymnosperm and deciduous angiosperm tree species on the functioning of temperate and boreal forests: spermatophytes and forest functioning. Biol Rev 90:444-466. https://doi.org/10. 1111/brv.12119

Baeten L, Verheyen K et al (2013) A novel comparative research platform designed to determine the functional significance of tree species diversity in European forests. Perspect Plant Ecol Evol Syst 15:281-291. https://doi.org/10.1016/j.ppees.2013.07.002

Besag J, Clifford P (1989) Generalized Monte Carlo significance tests. Biometrika 76:622-642

Beugnon R, Steinauer K, Barnes AD et al (2019) Plant functional trait identity and diversity effects on soil meso- and macrofauna in an experimental grassland. Advances in ecological research. Elsevier, pp 163-184

Blackburn J, Farrow M, Arthur W (2002) Factors influencing the distribution, abundance and diversity of geophilomorph and lithobiomorph centipedes. J Zool 256:221-232. https://doi.org/10.1017/ S0952836902000262

Borcard D, Gillet F, Legendre P (2018) Numerical ecology with R. Springer, Cham. https://doi.org/10.1007/978-3-319-71404-2

Burnham KP, Anderson DR, Burnham KP (2002) Model selection and multimodel inference: a practical information-theoretic approach, 2nd edn. Springer, New York

Chamagne J et al (2016) Do the rich get richer? Varying effects of tree species identity and diversity on the richness of understory taxa. Ecology 97:2364-2373. https://doi.org/10.1002/ecy.1479

Coulis M et al (2016) Leaf litter consumption by macroarthropods and burial of their faeces enhance decomposition in a mediterranean ecosystem. Ecosystems 19:1104-1115. https://doi.org/10.1007/ s10021-016-9990-1

Desie E, Vancampenhout K, Heyens K et al (2019) Forest conversion to conifers induces a regime shift in soil process domain affecting carbon stability. Soil Biol Biochem 136:107540. https://doi.org/ 10.1016/j.soilbio.2019.107540

De Wandeler H et al (2016) Drivers of earthworm incidence and abundance across European forests. Soil Biol Biochem 99:167-178. https://doi.org/10.1016/j.pedobi.2018.01.003

De Wandeler $\mathrm{H}$ et al (2018) Tree identity rather than tree diversity drives earthworm communities in European forests. Pedobiologia 67:16-25. https://doi.org/10.1016/j.pedobi.2018.01.003
Gamfeldt L et al (2013) Higher levels of multiple ecosystem services are found in forests with more tree species. Nat Commun 4:1340. https://doi.org/10.1038/ncomms2328

Garnier E et al (2004) Plant functional markers captures ecosystem properties during secondary succession. Ecology 85:2630-2637. https://doi.org/10.1890/03-0799

Gilliam FS (2007) The ecological significance of the herbaceous layer in temperate forest ecosystems. Bioscience 57:845-858. https:// doi.org/10.1641/B571007

Hansen RA, Coleman DC (1998) Litter complexity and composition are determinants of the diversity and species composition of oribatid mites (Atari: Oribatida) in litterbags. Appl Soil Ecol 9:17-23. https://doi.org/10.1016/S0929-1393(98)00048-1

Harrison XA et al (2018) A brief introduction to mixed effects modelling and multi-model inference in ecology. PeerJ 6:1-32. https:// doi.org/10.7717/peerj.4794

Hättenschwiler S et al (2005) Biodiversity and litter decomposition in terrestrial ecosystems. Annu Rev Ecol Evol Syst 36:191-218. https://doi.org/10.1146/annurev.ecolsys.36.112904.151932

Hedde M, Bureau F, Chauvat M, Decaëns T (2010) Patterns and mechanisms responsible for the relationship between the diversity of litter macro-invertebrates and leaf degradation. Basic Appl Ecol 11:35-44. https://doi.org/10.1016/j.baae.2009.10.009

Henneron L et al (2015) Forest management adaptation to climate change: a Cornelian dilemma between drought resistance and soil macro-detritivore functional diversity. J App Ecol 52:913-927. https://doi.org/10.1111/1365-2664.12440

Ives AR (2015) For testing the significance of regression coefficients, go ahead and log-transform count data. Methods Ecol Evol 6:828835. https://doi.org/10.1111/2041-210X.12386

Jost L (2006) Entropy and diversity. Oikos 113:363-375. https://doi. org/10.1111/j.2006.0030-1299.14714.x

Jucker $\mathrm{T}$ et al (2015) Crown plasticity enables trees to optimize canopy packing in mixed-species forests. Funct Ecol 29:1078-1086. https://doi.org/10.1111/1365-2435.12428

Kaneko N, Salamanca E (1999) Mixed leaf litter effects on decomposition rates and soil microarthropod communities in an oak-pine stand in Japan. Ecol Res 14:131-138. https://doi.org/10.1046/j. 1440-1703.1999.00292.x

Kaspari M (2001) Taxonomic level, trophic biology and the regulation of local abundance. Glob Ecol Biogeogr 10:229-244. https://doi. org/10.1046/j.1466-822X.2001.00214.X

Kaspari M, Yanoviak SP (2009) Biogeochemistry and the structure of tropical brown food webs. Ecology 90:3342-3351. https://doi. org/10.1890/08-1795.1

Kaspari M, O'Donnell S, Kercher JR (2000) Energy, density, and constraints to species richness: ant assemblages along a productivity gradient. Am Nat 155:280-293. https://doi.org/10.1086/303313

Kassambara A (2019) Package "factoextra". CRAN 1-77

Korboulewsky N, Perez G, Chauvat M (2016) How tree diversity affects soil fauna diversity: a review. Soil Biol Biochem 94:94106. https://doi.org/10.1016/j.soilbio.2015.11.024

Lavelle P, Spain AV (2001) Soil ecology. Kluwer Academic Publishers, Dordrecht

Legendre P, Anderson MJ (1999) Distance-based redundancy analysis: testing multispecies responses in multifactorial ecological experiments. Ecol Monogr 69:24. https://doi.org/10.1890/00129615(1999)069[0001:DBRATM]2.0.CO;2

Magnusson A, Skaug H, Nielsen A, et al (2019) Package "glmmTMB". CRAN 1-32

Monk CD (1966) An ecological significance of evergreenness. Ecology 47:504-505. https://doi.org/10.2307/1932995

Mueller KE, Eisenhauer N, Reich PB et al (2016) Light, earthworms, and soil resources as predictors of diversity of 10 soil invertebrate groups across monocultures of 14 tree species. Soil Biol Biochem 92:184-198. https://doi.org/10.1016/j.soilbio.2015.10.010

\section{Springer}


Nadrowski K, Wirth C, Scherer-Lorenzen M (2010) Is forest diversity driving ecosystem function and service? Curr Opin Environ Sustain 2:75-79. https://doi.org/10.1016/j.cosust.2010.02.003

Nakagawa S, Schielzeth H (2013) A general and simple method for obtaining $R^{2}$ from generalized linear mixed-effects models. Methods Ecol Evol 4:133-142. https://doi.org/10.1111/j.2041-210x. 2012.00261.x

Oksanen, J. et al. 2019. Package "vegan". CRAN, pp 1-296.

Ott D, Digel C, Klarner B et al (2014) Litter elemental stoichiometry and biomass densities of forest soil invertebrates. Oikos 123:1212-1223. https://doi.org/10.1111/oik.01670

Paivinen R, European Commission, Joint Research Centre, European Forest Institute (2001) Combining earth observation data and forest statistics. European Forest Institute, Joensuu

Pakeman RJ, Stockan JA (2014) Drivers of carabid functional diversity: abiotic environment, plant functional traits, or plant functional diversity? Ecology 95:1213-1224. https://doi.org/10.1890/ 13-1059.1

Perry KI, Herms DA (2016) Response of the forest floor invertebrate community to canopy gap formation caused by early stages of emerald ash borer-induced ash mortality. For Ecol Manag 375:259-267. https://doi.org/10.1016/j.foreco.2016.05.034

Pielou EC (1966) The measurement of diversity in different types of biological collections. J Theor Biol 13:131-144. https://doi.org/ 10.1016/0022-5193(66)90013-0

Ponge J-F (2003) Humus forms in terrestrial ecosystems: a framework to biodiversity. Soil Biol Biochem 35:935-945. https://doi.org/10. 1016/S0038-0717(03)00149-4

Prescott CE (2002) The influence of the forest canopy on nutrient cycling. Tree Physiol 22:1193-1200. https://doi.org/10.1093/ treephys/22.15-16.1193

Prescott CE, Vesterdal L (2013) Tree species effects on soils in temperate and boreal forests: emerging themes and research needs. For Ecol Manag 309:1-3. https://doi.org/10.1016/j.foreco.2013. 06.042

R Core Team (2019) R: a language and environment for statistical computing language and environment for statistical computing. CRAN

Reich PB et al (2005) Linking litter calcium, earthworms and soil properties: a common garden test with 14 tree species. Ecol Lett 8:811-818. https://doi.org/10.1111/j.1461-0248.2005.00779.x

Root RB (1973) Organization of a plant-arthropod association in simple and diverse habitats: the fauna of collards (Brassica Oleracea). Ecol Monogr 43:95-124. https://doi.org/10.2307/1942161

Salamon J-A, Zaitsev A, Gärtner S, Wolters V (2008) Soil macrofaunal response to forest conversion from pure coniferous stands into semi-natural montane forests. Appl Soil Ecol 40:491-498. https:// doi.org/10.1016/j.apsoil.2008.07.004

Salmon S, Artuso N, Frizzera L, Zampedri R (2008) Relationships between soil fauna communities and humus forms: response to forest dynamics and solar radiation. Soil Biol Biochem 40:17071715. https://doi.org/10.1016/j.soilbio.2008.02.007

Schelfhout S, Mertens J, Verheyen K et al (2017) Tree species identity shapes earthworm communities. Forests 8:85. https://doi.org/10. 3390/f8030085
Scherber C et al (2010) Bottom-up effects of plant diversity on multitrophic interactions in a biodiversity experiment. Nature 468:553556. https://doi.org/10.1038/nature09492

Scherer-Lorenzen M et al (2005) Forest diversity and function: temperate and boreal systems. Springer

Scheu S, Falca M (2000) The soil food web of two beech forests (Fagus sylvatica) of contrasting humus type: stable isotope analysis of a macro- and a mesofauna-dominated community. Oecologia 123:285-296. https://doi.org/10.1007/s004420051015

Scheu S, Albers D, Alphei J et al (2003) The soil fauna community in pure and mixed stands of beech and spruce of different age: trophic structure and structuring forces. Oikos 101:225-238. https://doi.org/10.1034/j.1600-0706.2003.12131.x

Schuldt A, Fahrenholz N, Brauns M et al (2008) Communities of ground-living spiders in deciduous forests: does tree species diversity matter? Biodivers Conserv 17:1267-1284. https://doi.org/10. 1007/s 10531-008-9330-7

Schwarz B, Dietrich C, Cesarz S et al (2015) Non-significant tree diversity but significant identity effects on earthworm communities in three tree diversity experiments. Eur J Soil Biol 67:17-26. https:// doi.org/10.1016/j.ejsobi.2015.01.001

Sklodowski JW (2002) Epigeic carabid assemblages of the Bialowieza primeval forest. How to protect or what we know about carabid beetles. Warsaw Agricultural University Press, pp 259-272

Sterner RW, Elser JJ (2002) Ecological stoichiometry: the biology of elements from molecules to the biosphere. Princeton University Press, Princeton

Storch D, Šizling AL (2008) The concept of taxon invariance in ecology: do diversity patterns vary with changes in taxonomic resolution? Folia Geobot 43:329-344. https://doi.org/10.1007/ s12224-008-9015-8

Thomas SC, Halpern CB, Falk DA et al (1999) Plant diversity in managed forests, understory responses to thinning and fertilization. Ecol Appl 9:16. https://doi.org/10.1890/1051-0761(1999) 009[0864:PDIMFU]2.0.CO;2

Turner JRG, Gatehouse CM, Corey CA (1987) Does solar energy control organic diversity? Butterflies, moths and the british climate. Oikos 48:195. https://doi.org/10.2307/3565855

Wall DH et al (2012) Soil ecology and ecosystem services. Oxford University Press

Wardle DA (2004) Ecological linkages between aboveground and belowground biota. Science 304:1629-1633. https://doi.org/10. 1126/science. 1094875

Williams PH, Gaston KJ (1994) Measuring more of biodiversity: can higher-taxon richness predict wholesale species richness? Biol Conserv 67:211-217. https://doi.org/10.1016/0006-3207(94) 90612-2

Zanella A, Jabiol B, Ponge JF et al (2011) A European morpho-functional classification of humus forms. Geoderma 164:138-145. https://doi.org/10.1016/j.geoderma.2011.05.016 


\begin{tabular}{|ll|}
\hline Journal: & $\mathbf{4 4 2}$ \\
Article: & $\mathbf{4 9 3 1}$ \\
\hline
\end{tabular}

\section{Author Query Form}

\section{Please ensure you fill out your response to the queries raised below and return this form along with your corrections}

Dear Author

During the process of typesetting your article, the following queries have arisen. Please check your typeset proof carefully against the queries listed below and mark the necessary changes either directly on the proof/online grid or in the 'Author's response' area provided below

\begin{tabular}{|l|l|l|}
\hline Query & Details Required & Author's Response \\
\hline AQ1 & $\begin{array}{l}\text { Please confirm if the author names are presented accurately and in the correct } \\
\text { sequence (given name, middle name/initial, family name) for author [Luis Daniel } \\
\text { Prada-Salcedo]. Also, kindly confirm the details in the metadata are correct. }\end{array}$ & $\begin{array}{l}\text { Kindly check whether Organisation division, name and address are correct in all } \\
\text { affiliations are correct and amend if needed. }\end{array}$ \\
\hline AQ2 & $\begin{array}{l}\text { Affiliation [8] has been split into two different affiliations. Please check if action taken } \\
\text { is appropriate and amend if necessary. }\end{array}$ & $\begin{array}{l}\text { AUTHOR: Ampoorter et al. 2020 has been changed to Ampoorter, et al., 2019 so that } \\
\text { this citation matches the Reference List. Please confirm that this is correct. }\end{array}$ \\
\hline AQ4 & $\begin{array}{l}\text { Kindly provide complete details for Refs. (Kassambara 2019, Magnusson et al. 2019, } \\
\text { Oksanen et al. 2019, R Core Team 2019). }\end{array}$ & $\begin{array}{l}\text { References (Decaëns 2010, Decaëns et al. 2010, Andersen 1995, Aubert et al. 2006) } \\
\text { was mentioned in the manuscript; however, this was not included in the reference } \\
\text { list. As a rule, all mentioned references should be present in the reference list. Please } \\
\text { provide the reference details to be inserted in the reference list. }\end{array}$ \\
\hline AQ6 & & \\
\hline
\end{tabular}

